\title{
Problems Existing in the Management of Contemporary College Students and Their Solutions
}

\author{
Cheng Yingying \\ Baicheng Normal University, Baicheng, China \\ 1318424420@qq.com
}

Keywords: Contemporary College, College Students, Management, Problems, Solutions

\begin{abstract}
The university education is also known as " elite education ", the students who can enter the university basically have strong learning ability and self - control, shoulder the hope of the future development of the motherland, and are also the successors of socialism. With the comprehensive deepening of the policy of university expansion in recent years, the number of national college students has been increasing year by year. Popularizing university education has become a hot topic, which plays an important role in improving the overall quality of our country. However, the development of this trend has led to many drawbacks, especially for the management of college students a huge challenge is put forward. Different from junior and senior high middle school, $90 \%$ of college students are away from home, and they study in college themselves, without parental care and companionship, and live in dorms. The living habits, local customs and other differences, will also affect the coexistence between each other. Once university management is not strict, it is easy to breed unhealthy atmosphere, affect students' studies, and even cause harm to students. In view of this situation, the management of college students in our country must be down-to-earth, from the actual situation of students, innovation management methods, and care for the mental health of students, so as to build a harmonious campus, so that students can grow up healthily.
\end{abstract}

\section{Introduction}

According to the investigation, with the introduction of the policy of colleges popularizing and expanding enrollment in our country, the quality of the college students is declining gradually, and the overall quality of the students is relatively weakened, which brings a great test to the management of the university. The educational department of our country has clearly put forward in the management standard of college students that "higher education should base itself on reality, and on the basis of achieving high quality teaching, it must strengthen management work, run schools according to law, run schools strictly, and formulate a sound management system to regulate the management behavior, considering the two aspects of teaching and management "[1]. In order to truly achieve the above goal, in order to perfect the teaching of colleges and universities under the background of the establishment of a knowledge-based country, we must strictly follow the norms to manage the whole school, carry out the responsibility of university management, and do a good job in the construction of spiritual civilization and campus culture, and constantly improve the comprehensive competitiveness of college students, so that colleges and universities have both first-class scientific research results and first-class management experience.

\section{The Core and Necessary Role of the Management of College Students}

The management of college students is not a simple teaching, but to carry out and implement the specific norms of education and teaching. In accordance with the concept of "student-oriented", we should do a good job of "educating people", and carry out management around the development of students. In the past, the teaching in colleges and universities paid attention to achievements and scientific research, and the management of students was a mode of "I take care of you", which was 
inconsistent with the modern teaching idea, was not conducive to promoting the development of college students, and also affected the construction of harmonious campus. The scientific and effective management of college students should grasp the fundamentals, manage the students' study, life, psychology and health, help them to shape their sound personality, and mobilize the students' subjective initiative and creativity through management, and enhance their sense of responsibility and tap students' potential abilities. In other words, the management of contemporary college students should take "people" as the core, find the effective way of "educating people" and strengthen the management from many angles [2]. In this way, students' comprehensive quality can be comprehensively improved, and they are more active in knowledge learning, and also have a better ability to analyze and solve problems. Even in the face of difficulties, they can maintain a positive and objective mentality. Improve your organizational skills and creativity. At the same time, for the whole school construction, strengthening the management of college students is also helpful to the creation of campus culture, to create a harmonious and cohesive collective, to provide a better learning atmosphere for students, and to have a good relationship between teachers and students, pushing the campus to a better direction [3].

\section{Problems in the Management of Contemporary College Students}

\subsection{Management Concept is Relatively Backward.}

Healthy, scientific and advanced management concept is the key to assist the teaching, improve teaching quality and management effectiveness. But at present, some colleges and universities have lagged behind in management thinking, have not kept pace with the development of the times, have less understanding of college students' psychology, and it is difficult to achieve good results in the management of "preaching". To put it simply, the management of college students is not based on reality, the concept of humanism can not be demonstrated, the management is school-based, students are in the position of passive servitude. Some school leaders and management teachers are too self-conscious to allow anyone to challenge their authority, and traditional management concepts are still dominant [4].

\subsection{Problems in the Development of College Students.}

Due to the expansion of enrollment in colleges, the rapid economic development of our country and the rising living standards of the people, contemporary college students pay more attention to their self-awareness and have a stronger sense of self-awareness than previous college students. However, there must be inevitable conflict between these and the traditional management mode. In addition, with the gradual expansion of the enrollment scope of colleges and universities, a large number of college students from all parts of the country and even from abroad live in such a relatively closed environment. How to adjust the living background, living environment and living habits of different students has become a special problem that the administrators of colleges and universities should pay attention to.

\subsection{Lack of a Sound Management System.}

A sound and perfect university management system is the basis of carrying out the internal management regulations and carrying out the management by scientific method. It is also the basis of the distribution of power and responsibility, which plays an important role in coordinating management [5]. However, many colleges and universities do not pay enough attention to the student management work, do not make a perfect management system according to their own actual situation, are lack the basis and feasible scheme of internal management, and the means of management lag behind. At the same time, there is no corresponding incentive mechanism for the management of college students.

\subsection{The Comprehensive Quality of University Management Staff Needs to be Improved.}

As the responsible person and executor of college students' management, the importance of managing teachers is self-evident. In a sense, their management level and comprehensive quality 
directly determine the quality of campus management, and is also the key for college students to take the initiative to accept management and consciously abide by campus regulations. In fact, the management of college students is not impossible to explore, from the students behavior, psychology, habits, the management law and feasible methods can be explored out of. However, some university students administrators have not observed them carefully, and have turned a blind eye to the publicity of college students' self-awareness and lack of creativity in their management work, which naturally easily leads to the phenomenon that management does not match the needs of students, that invisibly increases the difficulty of management [6].

\section{The Main Reasons for the Problems Existing in the Management of Contemporary College Students}

The positive and accurate analysis of the problems encountered in the management of contemporary college students and the exploration of the causes of these problems are the only way out of the dilemma and the only way to further strengthen the management, as well as the inevitable choice of constructing of a harmonious campus and cultivating high quality college students. In view of the above mentioned difficulties in the management of college students at this stage, the following reasons are obtained.

Firstly, the number of college students is increasing, while the overall quality is declining. Comprehensive improvement of higher education in China, aims to cultivate high quality students, improve the national integrity and promote the development of the country. However, because of the implementation of the policy of enlarging enrollment, the students' overall quality has declined, and some college campuses are born. Without protection, students' self-control is poor, which poses a great challenge to the management of colleges and universities. At the same time, the admission of undergraduate colleges and universities is based on the results, and often neglects the students' ideological and moral qualities, which leads to the low overall quality of college students [7].

Secondly, the current management system affects the management of college students. In college, the concept of class is weakened. The collective consciousness of college students is looser and looser, but the students' management work is mainly based on class, and its actual effect is weakened because of the loose class management. The corresponding work of university management is assigned to the counselors' shoulders, which is different from the middle and high school class teachers. The daily contact between counselors and students is less, and there is less connection in teaching, so the management effect of counselors is weak. At the same time, the university teaching system has also caused certain difficulties to the student management, such as the reform of the school running system, the big curriculum system, the innovation of the teaching mode and so on, which has become a new problem in the management work.

Thirdly, the development of network affects college students. Network technology, as the greatest invention, provides very convenient conditions for people life, study and work. People can learn all kinds of information from home and browse all over the world. Because of this, it is difficult to distinguish the authenticity of network messages, some bad content and vulgar segments began to spread, college students have poor self-control, lack of discernibility, sometimes indulging in the phenomenon of network addiction can not be extricated. Such as WeChat, Weibo, online shopping and other channels of communication and entertainment also occupy too much time for students, virtually increasing the difficulty of university management.

Finally, the rapid development of contemporary social impact on the management of college students. At present, China is in a period of rapid development, a new round of reform horn has been sounded, compared with before, the quality of life of the people has had a qualitative leap, the competition between the market is becoming more and more fierce. However, there are contradictions between the market and supply and demand, and the professional ability and quality level of college students can not meet the requirements of the employing unit, which contrasts that the management work of college students is out of step with the development of the times. 


\section{Effective Measures to Solve the Problems Existing in the Management of Contemporary College Students}

\subsection{Renewing the Concept of College Student Management.}

Innovative management concept is the fundamental to ensure the management of college students, and also the key to improve the effectiveness of management. In the past, the backward management thought should be firmly eliminated, the management should be carried out from the point of view of the students, the new management method should be created based on the reality, and the most ideal management mode should be explored. In this regard, managers should learn the latest management methods, strengthen the teaching of psychology courses, communicate more with students, and listen to students opinions and respect their views To create a scientific management system for college students when drawing up a standardized system.

\subsection{Strengthening the Socialization Management of College Students.}

The rapid development of the Internet makes the student management work can no longer be as the same as in the past, the rapid development of the information society makes students be able to fully understand the student management information in other universities. Therefore, under the new situation, the management departments of colleges and universities should exchange their experiences with each other, keep pace with the times, learn from the management experiences of other colleges and universities, and find out the defects of their own management. In addition, the management interaction between colleges and society is also a part of the socialization of college students' management. Among them, the management interaction between college and student family is the key of management socialization. Colleges and universities must pay attention to the family situation of students, especially students with special circumstances. According to the specific and practical situation of students families, the school should adopt appropriate, flexible and proper management methods to ensure that the students can complete their college study and life very well [8].

\subsection{Carrying out the Work of Safety Management.}

Safety management is the most important part of the management of college students in the contemporary universities and colleges. It can be seen from the frequent jumping events of colleges and universities in recent years. In order to carry out safety management and take care for the safety of the campus in many ways, we should pay more attention to the students, take safe precautions against their mental health, carry out more life teaching and talk more about life education. For students with special family and relatively weak psychology, the student work manager should prevent them from being in the bud and infect them with positive and optimistic attitude. Once the students are found to have unstable emotions, that should be killed in time. In addition, as the responsible person for the management of college students, it is necessary to pay more attention to the attendance system so as to ensure that the students return to school in time and not to return to the night. The phenomenon of lodging should be resolutely eliminated.

\subsection{Fully Respecting the Personalized Development of College Students.}

For the contemporary new forms of college students, the traditional rigid management concept and model can not meet the needs of the rapid development of the current society. Therefore, the individualized management concept and mode will become the development direction of the current university management. Nowadays, college students have stronger self-consciousness, which covers some degree of selfishness, but its main connotation is the individuation of students' psychology, mentality, cognition and behavior. Colleges and universities should formulate relative independent and purposeful management measures on the basis of meeting the basic management requirements and spirit. The management of college students needs the joint participation of university leaders, educational management departments, society and students' families in order to ensure the smooth progress of management of college students. 


\section{Conclusion}

The innovation and reform of university management is of vital significance to the development of education in the new era. Under the background of the extremely rapid development of contemporary society, the management of college students should be carried out in practice and analyze the existing problems in the past from the perspective of students. Based on safety management, learning management, psychological management and other problems to be solved, it is very necessary to establish a sound management system, update the concept of management, and respect the individual development of students for the college management, so as to build a harmonious campus suitable for learning.

\section{References}

[1] Yang Chenxia. Study on the change of university students management from administrative to professional at present [J]. Journal of Dalian University, 2017, 38(06):126-130.

[2] Sun Yu. Problems existing in the management of contemporary college students and their solutions [J]. Journal of Jilin Medical University, 2017, 38(04):319-320.

[3] Chen Shanshan. Using laws to convince people and moving people by emotion to promote the Innovation of university campus management model [J]. Journal of Jiamusi Vocational Institute, 2016(12):222-223.

[4] Zhuang Xiqing, Yu Xuan. Research on the Innovation of college students management work [J]. Journal of Chifeng University (Natural Science Edition), 2015, 31(22):237-238.

[5] Wu Longshui. Research on the innovation of college students management under multi-angle[J]. Journal of Chifeng University (Natural Science Edition), 2015, 31(21):212-213.

[6] Zhu Nan, Wang Shuopeng. Reflections on Counselors' subsidization and management of impoverished college students [J]. Brand, 2014(11):288.

[7] Kuang Yiyun. Management of contemporary college students and its reflections [J]. Journal of Sichuan Tourism University, 2011(04):101-103.

[8] Zhang Xiaobao, Zhang Jingqun. Probe into the management of college students from the perspective of social gende [J]. Journal of Changchun Normal University, 2011, 30(02):126-129. 